\title{
Use of class $\mathrm{C}$ fly ash for stabilization of fine-grained soils
}

\author{
Canan Turan ${ }^{1 *}$, Akbar Javadi ${ }^{1}$, Raffaele Vinai ${ }^{1}$, Nader Shariatmadari ${ }^{2}$, Raziyeh Farmani ${ }^{1}$ \\ ${ }^{1}$ Department of Engineering, University of Exeter, Exeter, EX4 4QF, UK \\ ${ }^{2}$ Department of Civil Engineering, Iran University of Science and Technology, Tehran, Iran
}

\begin{abstract}
Fine-grained soils may have undesired characteristics such as high swelling potential and low strength, thus requiring improvements. One of the stabilization methods involves the use of fly ash. Fly ash is a waste material obtained from burning coal in thermal power plants. The use of fly ash is encouraged as an alternative material for soil stabilization, due to its features such as pozzolanic properties and economic availability. This paper describes the results of an experimental study on stabilization of a clayey soil with fly ash. Unconfined compressive strength (UCS), triaxial and consolidation tests were carried out on samples of kaolinite mixed with class $\mathrm{C}$ fly ash at different percentages and cured for 1, 7, and 28 days, in order to study the effects of class $\mathrm{C}$ fly ash on the mechanical behaviour of the stabilized soil. The results showed that the inclusion of fly ash significantly improves the strength characteristics of the soil. Curing time was also found to have a significant effect on improving the properties of the soil.
\end{abstract}

\section{Introduction}

Soil stabilization is a modification of some characteristics of a weak soil to make sure its stability on construction [1]. Damage to geotechnical engineering structures owing to the weak soils could be very costly. The annual cost of damage to structures is approximately $\$ 1000$ million in the US, £ 150 million in the UK, and several billions of dollars worldwide [2]. Many researchers have attempted to improve traditional and non-traditional chemical soil stabilization methods to prevent this major damage. Non-traditional methods include the use of silicates, acids, resins, liquid polymers, and lignin derivatives [3]. These methods are becoming more common because of the rising demand for stabilization of weak soils. However, one of the main disadvantages of these methods is the lack of information on environmental effects. The use of fly ash (which is a waste material obtained from burning of coal) for soil stabilization may be considered as a traditional method. The use of fly ash has been recommended by many investigators due to the many additional benefits, such as being environmentally friendly and cost-effective, as well as its ease of adaptability.

Fly ash can be separated into two types, class $\mathrm{C}$ fly ash and class F fly ash. Class $\mathrm{C}$ fly ash includes selfcementing characteristics due to the high percentage of calcium oxide content $(\mathrm{CaO})$ (between $20 \%$ and $40 \%$ ), while class $\mathrm{F}$ fly ash has a calcium oxide content generally less than $12 \%$. In addition, class $\mathrm{C}$ fly ash has cementitious and pozzolanic properties and it is produced from low rank burning coals, lignites and subbituminous coals. On the other hand, class F fly ash has pozzolanic properties and it is produced from high-rank coals, anthracites or bituminous coals [4].

This paper investigates the effects of fly ash in stabilization of a common type of clayey soil. A series of experiments were carried out to evaluate the improvement in strength characteristics of kaolinite with the addition of different percentages of fly ash. The experiments included consolidated undrained (CU) triaxial tests with one day curing and unconfined compressive strength (UCS) tests with 1, 7, and 28 days of curing.

\section{Experimental Study}

\subsection{Materials}

\subsubsection{Soil}

A dry kaolinite powder, China clay, was used in this study. The clayey soil has maximum dry unit weight $\left(\gamma_{\text {dmax }}\right)$ of $1.51 \mathrm{Mg} / \mathrm{m}^{3}$, optimum moisture content $\left(\mathrm{w}_{\mathrm{opt}}\right)$ of $21 \%$, and a specific gravity of 2.6. The soil can be classified as clay with intermediate plasticity (CI) according to the Unified Soil Classification System (USCS).

\subsubsection{Fly ash}

The fly ash used in this experimental study was sourced from the MUEG company. According to the information provided by the supplier, its chemical composition includes $32.4 \%$ calcium oxide $(\mathrm{CaO}), 28.3 \% \mathrm{SiO}_{2}, 6.6$ $\% \mathrm{Fe}_{2} \mathrm{O}_{3}, 15.8 \% \mathrm{Al}_{2} \mathrm{O}_{3}, 0.5 \% \mathrm{~K}_{2} \mathrm{O}, 4.2 \% \mathrm{MgO}, 0.31 \%$

Corresponding author: ct554@exeter.ac.uk 
$\mathrm{Na}_{2} \mathrm{O}, 0.72 \% \mathrm{P}_{2} \mathrm{O}_{5}, 8.6 \% \mathrm{SO}_{3}, 0.9 \mathrm{TiO}_{2}$. Based on the ASTM C618 standard, the fly ash can be classified as a class $\mathrm{C}$ fly ash (considering the amount of $\mathrm{CaO}$ ).

\subsection{Method}

\subsubsection{Unconfined Compressive Strength Tests}

The fly ash contents of samples for UCS tests were $5 \%$, $10 \%, 15 \%, 20 \%, 25 \%$, and $30 \%$ based on the dry weight of the soil. These contents were specifically chosen based on recommendations from previous studies that the optimum strength level can be achieved with 20$25 \%$ fly ash [2] [3].

Samples of fly ash stabilized soil and pure soil were compacted in a specially designed mould using an Instron 3382 floor model universal testing system. This equipment allowed static compaction under a constant rate of loading up to a specified load. The maximum compaction load was $1.57 \mathrm{kN}$. The prepared samples, 50 $\mathrm{mm}$ in diameter and $100 \mathrm{~mm}$ in height, were subjected to uniaxial compressive strength tests at a loading rate of $1 \mathrm{~mm} / \mathrm{min}$ between two metal plates. The maximum dry unit weight of the compacted samples was between 1.48$1.52 \mathrm{Mg} / \mathrm{m}^{3}$ based on the different contents of fly ash. The optimum moisture content of the compacted samples was $26 \%$. The samples were cured for 1 day, 7 days, or 28 days before the UCS tests.

\subsubsection{Consolidated Undrained (CU) Triaxial Tests}

The CU triaxial tests were conducted to analyse maximum deviator stresses, cohesion, angle of shearing resistance and critical state parameters of fly ash stabilized soil with $0 \%$ (control sample), $15 \%$, and 25 $\%$ fly ash with 1 -day curing time.

The triaxial tests were carried out according to the British Standard, BS 1377-8 [5]. Saturation, saturation check (B-value check), consolidation, and shearing stages were conducted using a GDS triaxial testing system.

\section{Results and Discussions}

\subsection{Unconfined Compressive Strength Tests}

The relationship between peak unconfined compressive strength and fly ash content at different curing days is demonstrated in Figure 1. The figure clearly shows that the strength increased with increasing the fly ash content and with the curing time.

The effect of class $\mathrm{C}$ fly ash in improving the compressive strength of the soil was much higher with 7 and 28 days of curing times than with 1-day curing time. The unstabilized (control) soil samples had peak compressive stresses of $226 \mathrm{kPa}, 245 \mathrm{kPa}$, and $235 \mathrm{kPa}$ at 1,7 , and 28 days of curing time, respectively. A gradual increase was seen in the peak compressive stresses at 1-day curing time and the peak stress reached $295 \mathrm{kPa}$ with addition of $30 \%$ fly ash, whereas a sudden increase was observed in the stresses, specifically for 25 $\%$ and $20 \%$ fly ash, at 7 and 28 days of curing, respectively. The peak values were $517 \mathrm{kPa}$ with $25 \%$ fly ash at 7 days of curing and $599 \mathrm{kPa}$ at 28 days of curing. By increasing the fly ash content to $30 \%$, the peak stress decreased to the value of $442 \mathrm{kPa}$ at 7 days of curing, and $594 \mathrm{kPa}$ and $485 \mathrm{kPa}$ with $25 \%$ and $30 \%$ of fly ash at 28 days of curing.

It was observed that the curing time is an important parameter affecting the strength of the stabilized soil. This is owing to the cementitious and pozzolanic characteristics of the class $\mathrm{C}$ fly ash.

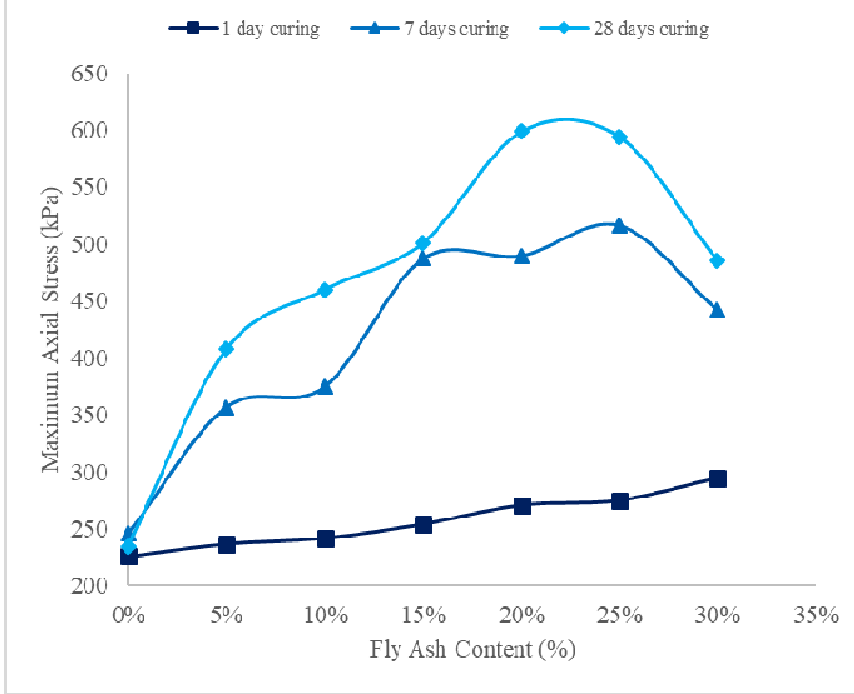

Fig. 1. Effects of fly ash content on unconfined compressive strength with 1,7 , and 28 days of curing.

The variations of the elastic modulus of the fly ash stabilized soil samples at 1,7 , and 28 days of curing time were obtained from the gradient of the linear-elastic sections of the stress-strain curves (Table 1). The results show a clear relationship between the class $\mathrm{C}$ fly ash content and the elastic modulus. In general, elastic modulus increased with increasing the fly ash content. This means that, under the same axial load, with the addition of fly ash the stabilized soil became stiffer and less compressible up to the yield point.

Table 1. Elastic modulus of fly ash stabilized soil at different curing times.

\begin{tabular}{|c|c|c|c|}
\hline & 1 day curing & 7 days curing & 28 days curing \\
\hline $\begin{array}{c}\text { Fly ash } \\
\text { content }\end{array}$ & \multicolumn{3}{|c|}{ Elastic Modulus (E) (MPa) } \\
\hline $0 \%$ & 9.5 & 5.4 & 6.1 \\
\hline $5 \%$ & 16.7 & 18.6 & 21.4 \\
\hline $10 \%$ & 19.3 & 19.5 & 25.5 \\
\hline $15 \%$ & 19.1 & 30.1 & 27.3 \\
\hline $20 \%$ & 22.8 & 37.5 & 47.2 \\
\hline $25 \%$ & 22.1 & 34.9 & 50.8 \\
\hline $30 \%$ & 25.1 & 21.5 & 34.4 \\
\hline
\end{tabular}




\subsection{Consolidated Undrained Triaxial tests}

\subsubsection{Effects of fly ash on stress-strain behaviour and strength of the soil}

Figure 2 shows the relationship between maximum deviator stress $\left(\mathrm{q}=\sigma_{1}-\sigma_{3}\right)$ and fly ash content $(\%)$ for each sample during the shearing stage. The control samples (pure kaolinite), at confining pressures of $300 \mathrm{kPa}, 600$ $\mathrm{kPa}$, and $900 \mathrm{kPa}$ were found the weakest based on the maximum deviator stresses. The results show an increase in strength with addition of $15 \%$ and $25 \%$ fly ash (Table 2). In addition, strength of the fly ash stabilized soil improved with increasing the confining pressure. A similar trend of variations is also obtained by Prabakar et al [6].

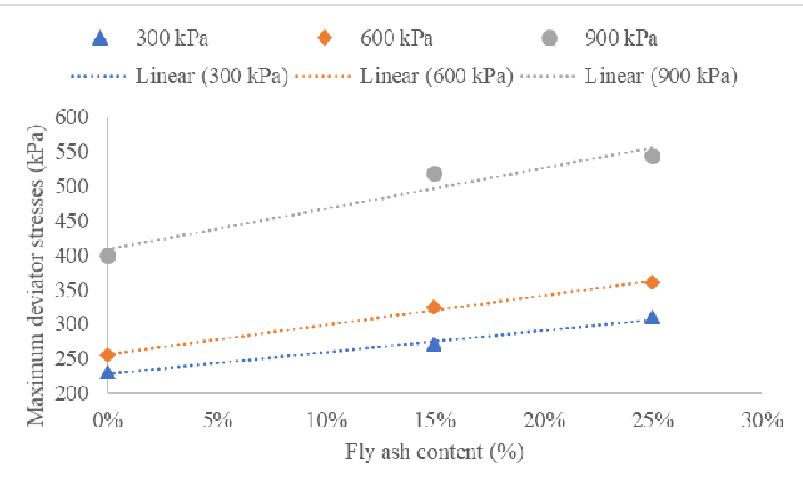

Fig. 2. Effects of fly ash content on peak deviator stress.

Table 2. Maximum deviator stresses of fly ash stabilized soil with $0 \%, 15 \%$, and $25 \%$ fly ash at 300,600 , and $900 \mathrm{kPa}$ confining pressures.

\begin{tabular}{|c|c|c|c|}
\hline & $300 \mathrm{kPa}\left(\sigma_{3}\right)$ & $600 \mathrm{kPa}\left(\sigma_{3}\right)$ & $900 \mathrm{kPa}\left(\sigma_{3}\right)$ \\
\hline $\begin{array}{c}\text { Fly ash } \\
\text { content }\end{array}$ & \multicolumn{3}{|c|}{ Maximum deviator stresses $(\mathrm{kPa})$} \\
\hline $0 \%$ & 230 & 255 & 399 \\
\hline $15 \%$ & 271 & 324 & 518 \\
\hline $25 \%$ & 310 & 360 & 543 \\
\hline
\end{tabular}

\subsubsection{Mohr-Coulomb Parameters}

The Mohr-Coulomb failure envelopes were produced from the results of the tests on the control samples and samples of stabilized soil with $15 \%$, and $25 \%$ fly ash. The values of effective apparent cohesion and the effective angle of shearing resistance are indicated in Figures 3, 4, and 5 for the control sample, and the samples stabilized with $15 \%$, and $25 \%$ fly ash. It is observed that the effective cohesion increased with increasing fly ash which was also reported by Phani Kumar and Sharma [2] and Prabakar et al [6]. The value of apparent cohesion was found $19.5 \mathrm{kPa}$ for the control sample. The sample stabilized with $15 \%$ fly ash indicated a significant increase in apparent cohesion with the value of $55 \mathrm{kPa}$. Increasing the fly ash from $15 \%$ to $25 \%$ showed a further increase in cohesion with the value of $58 \mathrm{kPa}$. This increase could be due the cementitious properties of fly ash stabilized soil. The angle of shearing resistance also improved with addition of fly ash. The value of angle of shearing resistance increased from 18.6 degrees for the control sample, to 21.3 degrees for the sample stabilized with $15 \%$ fly ash and then increased to 22.4 degrees with $25 \%$ fly ash content. It is seen that the increase in angle of shearing resistance is much higher from the control sample to the sample with $15 \%$ fly ash compared to $15 \%$ to $25 \%$ fly ash content. This could be due to the fact that the fly ash and kaolinite react until a certain percentage of fly ash, thereafter the improvement of angle of shearing resistance becomes less in stabilized soil because of the differences in particle sizes of fly ash and kaolinite.

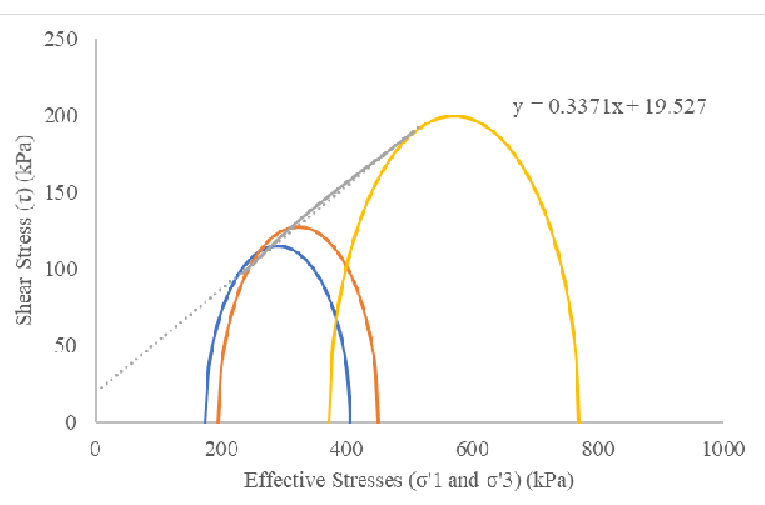

Fig. 3. Mohr circles and failure envelope for the control sample (pure kaolinite).

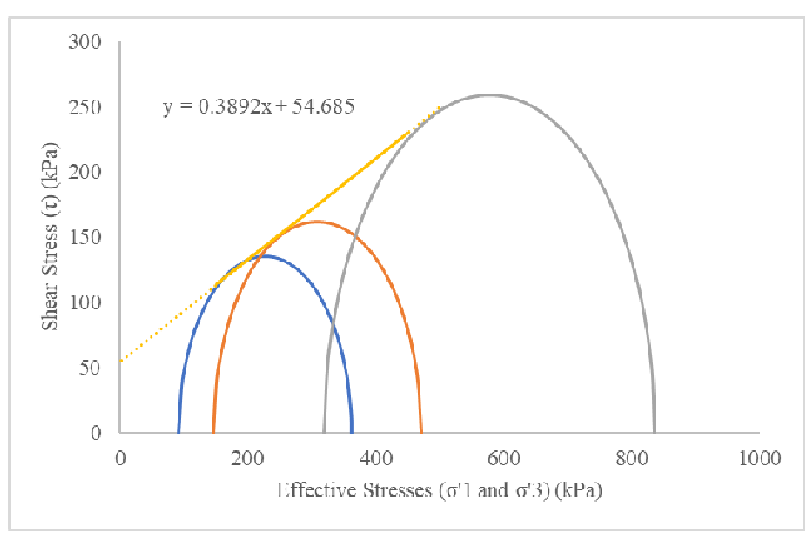

Fig. 4. Mohr circles and failure envelope for soil stabilized with $15 \%$ fly ash. 


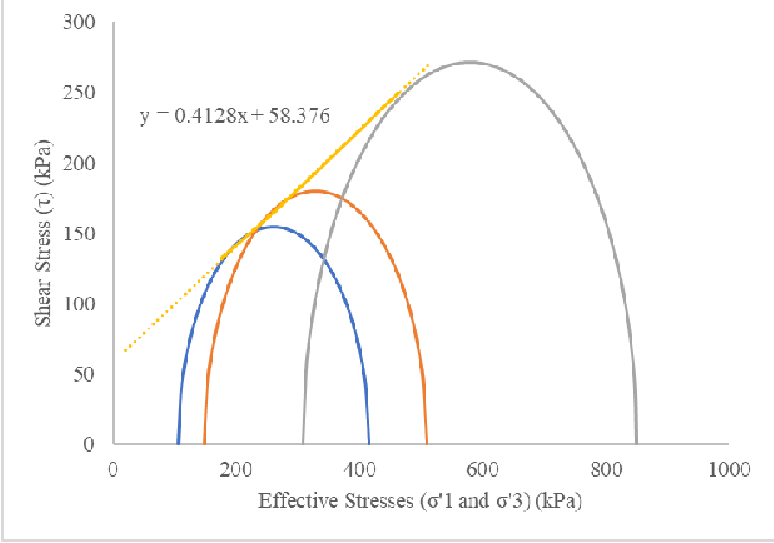

Fig. 5. Mohr circles and failure envelope for soil stabilized with $25 \%$ fly ash.

\subsubsection{Critical State Parameters}

Table 3 and Figure 6 demonstrate the critical state parameters that were obtained from the graphs of deviator stress (q) versus mean normal effective stress (p'). The critical state lines (CSLs) for the control sample and the fly ash stabilized soils with $15 \%$, and 25 $\%$ fly ash were plotted and the gradients (M) were calculated. The y-intercept of the critical state lines is related to the cohesion and is shown to increase with increasing the fly ash content. The gradient of the CSL (M) is a function of angle of shearing resistance and it increased from control sample to $15 \%$ and $25 \%$ fly ash content. These parameters also align with the MohrCoulomb Model results.

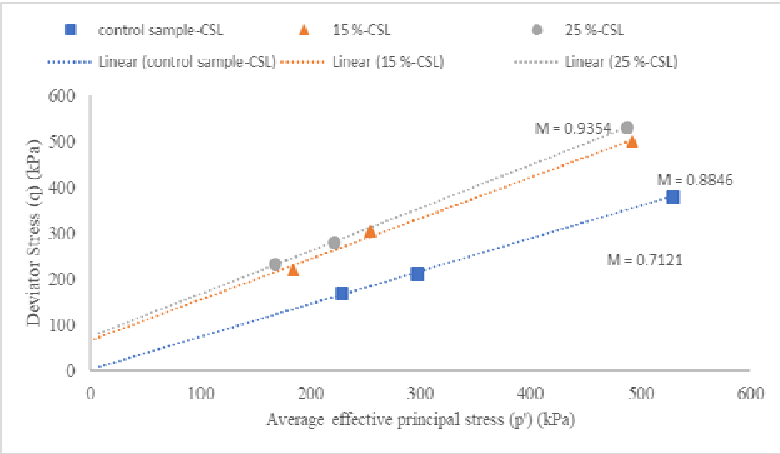

Fig. 6. Deviator stress versus mean effective stress with $0 \%$, $15 \%$, and $25 \%$ fly ash content.

Table 3. Critical state parameters are based on q-p' graph.

\begin{tabular}{|c|c|c|}
\hline Based on q-p' graph & $\mathrm{M}$ & $\begin{array}{c}\mathrm{y}- \\
\text { intercept }\end{array}$ \\
\hline $0 \%$ (control sample) & 0.7121 & $4 \mathrm{kPa}$ \\
\hline $15 \%$ fly ash content & 0.8846 & $67 \mathrm{kPa}$ \\
\hline $25 \%$ fly ash content & 0.9354 & $75 \mathrm{kPa}$ \\
\hline
\end{tabular}

The variations of specific volume (v) against mean effective normal stress are shown in Figures 7, 8, and 9 for the soils with different percentages of fly ash. The parameters $\lambda$ and $\Gamma$ parameters were evaluated from the equation;

$$
V=\Gamma-\lambda \ln \left(p^{\prime}\right)
$$

where $\Gamma$ is the value of $\mathrm{v}$ on the critical state line at $\mathrm{p}^{\prime}=1 \mathrm{kPa}$ and $\lambda$ is the gradient of the critical state line [7]. $\lambda$ also refers to the gradient of the isotropic normal compression line which gives the consolidation and settlement characteristics of the samples [7].

Based on the results obtained from the experiments, both $\lambda$ and $\Gamma$ decreased with increasing the fly ash content (Table 4). These results indicate that the compressibility of the fly ash stabilized soil decreases with fly ash content.

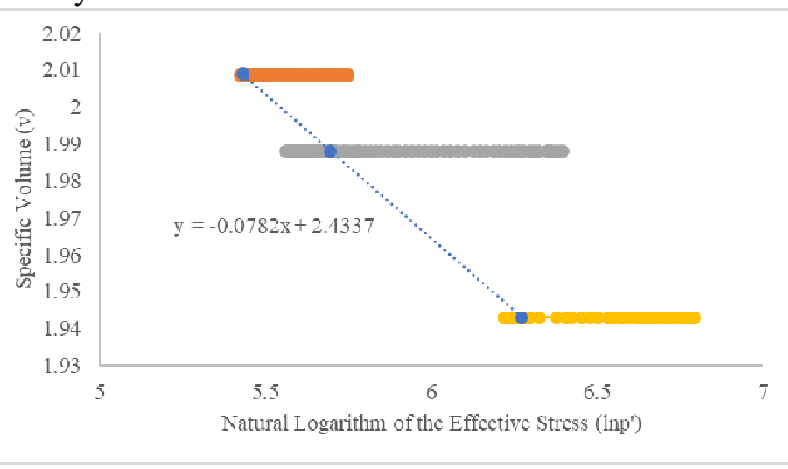

Fig. 7. $v$ : p' plot for soil with control sample.

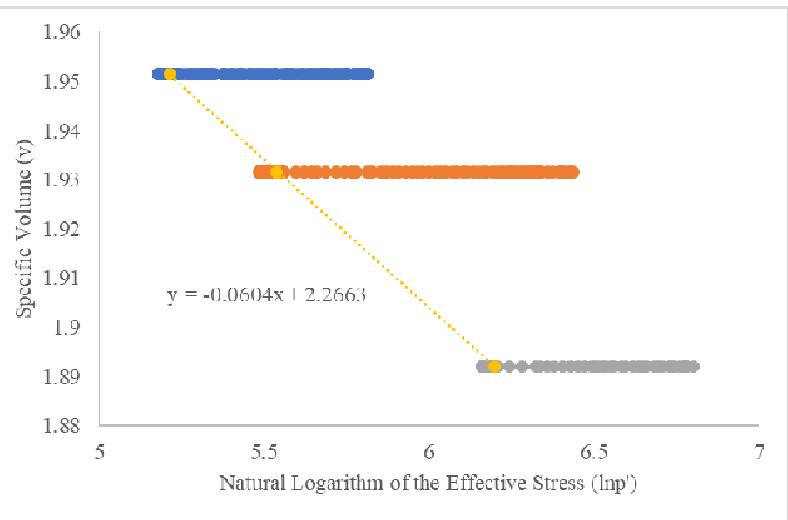

Fig. 8. $v$ : p' plot for soil with $15 \%$ fly ash.

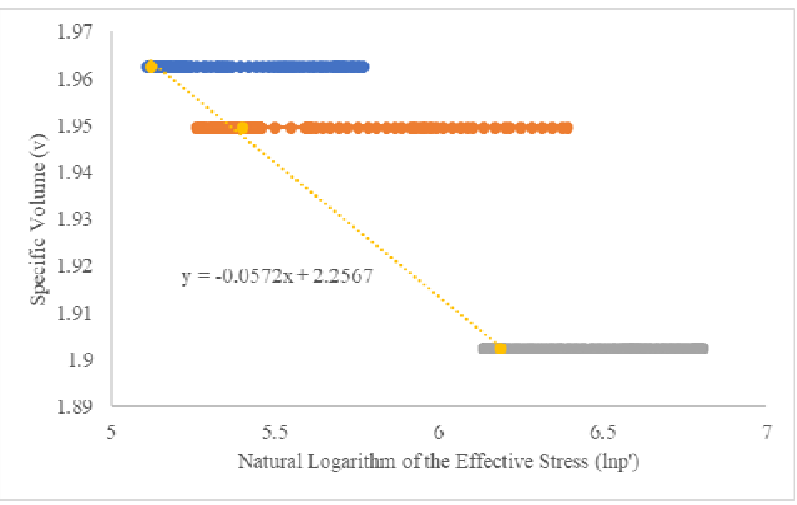

Fig. 9. v: p' plot for soil with $25 \%$ fly ash. 
Table 4. Critical state parameters are based on v-lnp' graph.

\begin{tabular}{|c|c|c|}
\hline Based on v-Inp' graph & $\boldsymbol{\lambda}$ & $\boldsymbol{\Gamma}$ \\
\hline $0 \%$ (control sample) & 0.0782 & 2.434 \\
\hline $15 \%$ fly ash content & 0.0604 & 2.266 \\
\hline $25 \%$ fly ash content & 0.0572 & 2.257 \\
\hline
\end{tabular}

\section{Conclusions}

A series of experiments were carried out to determine the effects of fly ash on the stress-strain behaviour and shear strength of a fine grained soil. The experiments included unconfined compressive strength (UCS) tests with 1 day, 7 days, and 28 days of curing, and CU triaxial tests with 1 day of curing. Based on the UCS test results, the compressive strength of the soil gradually increased with increasing the fly ash content. The strength parameters of fly ash stabilized soil with 7 days and 28 days of curing were much higher compared to the stabilized soil with 1 day of curing. This is due to the cementitious and pozzolanic characteristics of the class $\mathrm{C}$ fly ash. The results of the UCS tests also indicated that the elastic modulus of the soil increased with increasing the fly ash content of the stabilized soil with 1 day, 7 days, and 28 days of curing. The results from the $\mathrm{CU}$ triaxial tests also showed an increase in peak shear strength with the addition of fly ash. Moreover, an improvement in the values of cohesion intercept and angle of shearing resistance was observed for the soil stabilized with $15 \%$ and $25 \%$ fly ash. The compressibility parameters of the stabilized soil decreased with increasing the fly ash content.

These results indicate that class $\mathrm{C}$ fly ash can be used for stabilization of fine-grained soils to achieve a decrease in compressibility and improvement in the strength parameters, shear strength and bearing capacity.

The results demonstrated in this paper are a part of a large research program on the effects of fly ash stabilized soil and additional data will be presented in the conference.

\section{Acknowledgements}

The authors would like to thank the Turkish government for their financial support.

The project has also received funding from the European Union's Horizon 2020 research and innovation programme under the Marie Sklodowska-Curie grant agreement No 778120 .

\section{References}

1. S. H. Trinh, \& Q. A. T. Bui. Influencing of clay and binder content on compression strength of soft soil stabilized by geopolymer based fly ash. 13(10), 7954-7958 (2018)
2. B. R. Phani Kumar \& R. S. Sharma. Effect of fly ash on engineering properties of expansive soils. 130, 764-767 (2004)

3. E. Seyrek. Engineering behaviour of clay soils stabilized with class $\mathrm{C}$ and class F fly ashes. 25(2), 273-287 (2016)

4. M. Ahmaruzzaman. A review on the utilization of fly ash. 36 (3), 327-363 (2010)

5. BS 1377-8: 1990. Methods of test for soils for civil engineering purposes. Shear strength tests (effective stress). Retrieved from: https://bsol.bsigroup.com/Bibliographic/Bibliograph icInfoData/000000000000226601

6. J. Prabakar, N. Dendorkar \& R. K. Morchhale. Influence of fly ash on strength behaviour of typical soils. 18(4) 263-267 (2004).

7. R. Craig. Craig's soil mechanics seventh edition solutions manual. London: Spon. (2004). 